\title{
The Effect of Focus Strategies on ADHD Students' English Vocabulary Learning in Junior High School
}

\author{
Masoud Khalili Sabet \\ Dept. of English Language and Literature, Faculty of Humanities, University of Guilan \\ Rasht, Iran \\ E-mail:sabetma2002@yahoo.com \\ Fatemeh Farhoumand (Corresponding Author) \\ International Campus, University of Guilan \\ Rasht, Iran \\ E-mail: s_farhoumand85@yahoo.com \\ Amir Mahdavi Zafarghandi \\ Dept. of English Language and Literature, Faculty of Humanities, University of Guilan \\ Rasht, Iran \\ E-mail address: mahdavi1339@gmail.com \\ Ashkan Naseh \\ Shahed University of Tehran, Faculty of Humanities, University of Guilan \\ Rasht, Iran \\ E-mail: ashkan.naseh@yahoo.com
}

Received: 07-07-2014

doi:10.7575/aiac.ijalel.v.4n.1p.125
Accepted: 03-09-2014

Published: 01-01-2015

\begin{abstract}
"Attention deficit hyperactivity disorder (ADHD) is the most common neurobehavioral disorder of childhood. ADHD is also among the most prevalent chronic health conditions affecting school-aged children"(American Academy of Pediatrics, 2000). Too many young girls are not getting the help they need because of hidden symptoms and late diagnosis. The purpose of this study is to determine the effect of focus strategies on vocabulary learning of ADHD students at two junior high schools. To this end, eight female ADHD and eight normal students from two public schools were assigned to the both control group and the experimental one. The quantitative data was gathered from each student and was analyzed through 2-way analysis of variance (ANOVA) in a factorial arrangement with two repetitions. An orthogonal test was used to compare the strategies that were used in the control group (word list) and the experimental group (key word method, concentration, making sentences and fold overs). The instrument of this study contained a questionnaire sent to the parents and English teachers, an interview with a psychologist, a pre-test and a post-test. The results indicated that the four focus strategies in the experimental group increased the vocabulary learning in ADHD students for the short term retention and this increase was significant in the first focus strategy (key word method) and mostly the last one (fold overs) in the normal and ADHD students. The mean scores of control group were lower than the treatment group both in the normal and ADHD students. The results of delayed post-test revealed that although focus strategies improved the scores of the normal students compared to the ADHD students, this difference was not significant.
\end{abstract}

Keywords: ADHD, focus strategies, Key word method, fold overs, attention, two-way ANOVA

\section{Introduction}

Some teachers may have experiences with the students who do not focus on learning activities well, never seem to listen, cannot sit still and are always in motion, act without thinking, do not follow clear instructions and are daydreaming. They may understand what is expected of them, but they have trouble following through because of lack of attention to details and feeling bored to do the tasks. They lose things necessary for tasks and avoid, dislike and are reluctant to engage in the activities of the classroom. The students with these characteristics may be called undisciplined and troublemakers by the teachers, but these are the symptoms of Attention Deficit Hyperactivity Disorder (ADHD).

According to Grunter (2013, para. 1), ADHD is a chronic debilitating condition that affects approximately 5.4 million children and adolescents aged 4 to 17 in the United States. Prevalence estimates have varied from $3 \%$ to $7 \%$ in school aged children and recent parent surveys reveal that $9.4 \%$ of children aged 4 to 17 in the United States have been diagnosed with ADHD. In Iran, about $5 \%$ of school aged children have been diagnosed with ADHD. [Akhondzadeh, (personal communication, October 2, 2013)]. 
"Boys are diagnosed about four times as often as girls. This difference could be due to both a selection bias, since boys are more active, as well as to a true gender difference" (Grunter, 2013, para. 1). "Of course, all kids (especially younger ones) act this way at times, particularly when they are anxious or excited. But the difference with ADHD is that the symptoms in ADHD are present over a longer period of time and occur in different settings. They impair a child's ability to function socially, academically and at home"(Kingsley, 2012).

Based on the symptoms listed in its Diagnostic and Statistical Manual, the American Psychiatric Association has identified three subtypes of ADHD:

\section{ADHD, Combined Type: Both inattention and hyperactivity-impulsivity symptoms}

2. ADHD, Predominantly Inattentive Type: Inattention, but not enough (at least 6 out of 9 symptoms) hyperactivityimpulsivity symptoms.

3. ADHD, Predominantly Hyperactive-Impulsive Type: Hyperactivity-impulsivity, but not enough (at least 6 out of 9 symptoms) inattention symptoms.

Maintaining ADHD students' attention is a real challenge with which many teachers are confronted in the classrooms because most of the teachers do not know how to teach and behave them. If the teachers try to adopt the behavioral interventions and appropriate learning strategies, the quality of life in these students will be improved. This disorder affects the student's life at school, home and society. Mostly schools do not know how to maintain a proper care and support for these students. Parents are frustrated and depressed when they compare their children with normal ones. Classmates may ridicule them and threaten their self-esteem. These students are mostly appeared inattentive, aggressive, misbehaved and lonely.

Although medication may help some students to concentrate, many ADHD students can benefit from learning focus strategies. To Parker (2006), learning requires both understanding and memory. Without either it is impossible to fully benefit from education. Learning strategies are actions taken by the student to make learning easier, faster, more selfdirected, more effective, and transferrable to new situations (Oxford, 1990; cited in Scott\& Fark, 2011). Learning strategies do not teach students content. They do, however, teach students how to approach the content. Instead of teaching students multiplication facts, a learning strategy might teach students the steps necessary to solve a multiplication problems (Scott\& Compton, 2007; ibid.).

"For years, the popular methodology for learning a second language was to focus on grammar and sentences first and then on vocabulary. Recently, however, there has been a shift toward recognition that learning vocabulary first leads to more success" ("The five principles of effective second language acquisition,"2014, para. 1)

Without vocabulary knowledge, language production and comprehension would not be possible. Also, vocabulary is an element that links the four skills of speaking, listening, reading and writing. So, for communicating in a foreign language, the students should know and use adequate number of words.

A great number of studies have been done, as a result of which suggestions are made to improve the behavior of ADHD students. Turketi (2010) considered the process of second language acqusition for children with ADHD in terms of input and output speech issues, motivation problems and learning prefernces and presented ESL methodologies that can be applied effectively in addressing learners' needs and the rationale of their choice. Aizer (2008) showed that peer behavior is an important mechanism, perhaps more than ability, by exploiting exogenous timing in diagnosis treatment of ADD among peers that improves peer behavior while holding peer achievement constant. Oord, et al. (2012) evaluated the effectiveness of mindfulness training for children with ADHD and mindful parenting for parents. Bolin (2010) researched effective instruction strategies for children with attention deficits and the results revealed an increasing trend of desired on task behaviors from students with ADHD.

For thousands of years, cultures in every part of the world have developed techniques and systems of training attention: Tai-chi, yoga, meditation, visionary quests, rites of passage, reflection, reverie and more (Dang,1994; Goleman,1996; Lyengar,1995; cited in Armstrong,1999, p.6). Armstrong (1999) believes "there is scarcely a mention in the ADD/ADHD literature of any of these attention-training methods. In one study, adapted from an approach used by Harvard physician Herbert Benson (Benson \& Klipper,1990), kids labeled ADD/ADHD who were asked to focus on a sound for a few minutes each day, experienced less distractibility and impulsivity, and greater ability to attend (Kratter \& Hogan,1982). In other examples, the researchers trained kids to focus on images. Oaklander (1978) used a "roaming meditation " as a part of her work with children who could not hold their focus on a single object for more than a second or two (pp. 226-227)".

Yet, not much research has been done on investigating focus strategies for teaching vocabulary to ADHD students. Learning a foreign language usually is problematic for students with ADHD. In order to communicate well, they should acquire an adequate number of words, so vocabulary plays an important role in their learning. Because ADHD is a cognitive plroblem, cognitive learning strategies may help to increase such students attention and help them to focus. As it was mentioned before, there are three types of ADHD: hyperactive, inattentive and combined type. Girls show more inattentive type of ADHD (Gurian, n.d.) and are diagnosed later than boys. Because of ADHD students' learnig difficulties that affect their academic success, their behavior with parents, peers and teachers and because of growing prevalence of diagnosis of this disorder in the scociety and the importance that it has for education, this paper considers focus learning strategies on junior high school ADHD students so that they could overcome their problems and gain 
more in their academic achievements and open a way for teachers who wish their students' success and parents who always seek the best ways for their children 's progress.

\subsection{Research questions and hypotheses}

To conduct this investigation, the following research questions were formulated:

1. Does the vocabulary achievement by the ADHD students using the focus strategies improve at a statistically significant level?

2. What is the effect of focus strategies on the normal students?

Based on the research questions, the following hypotheses were proposed:

1. The vocabulary achievement by ADHD students using the focus strategies improve at a statistically significant level.

2. The effect of focus strategies is significant on the normal students.

\section{Method of the study}

\subsection{Participants}

To investigate the effect of the focus strategies on the vocabulary learning of ADHD students two junior high schools, Mohseni and Tahvildari, two female public schools in Rasht, Iran (an EFL based environment) were selected. Under the supervision of a psychologist, parents' forms were sent to the students' parents which had 18 criteria of DSM-IV previously standardized in Iran. It is based on "the Child Symptom Inventory-4 (CSI-4) which is a behavior rating scale that screens for DSM-IV emotional and behavioral disorders in children. CSI-4 scores demonstrate satisfactory testretest reliability, show a high degree of correspondence with psychiatric diagnosis (predictive validity), and correlate well with other commonly used dimensional scales (concurrent validity)" (Gadow \& Sprafkin,1994; Mohammd Esmaeil \& Alipour, 2002).

Eleven students were diagnosed ADHD based on common and overlapping features of two forms in Mohseni's school that showed 3.9\% ADHD occurrence rate whereas four students were diagnosed in Tahvildari's school that showed 4.5\% ADHD occurrence rate. All of the cases showed the symptoms of inattentive (that is more common in the girls, Gurian, n.d.) than hyperactivity or combined type (that is more common in the boys; ibid.). So, this study considered the amount of vocabulary learning.

Mohseni's school was chosen to serve as the ADHD student group whereas one class in Tahvildari's school was chosen to serve as the normal student group. The psychologist interviewed the diagnosed ADHD students one by one and confirmed the signs of ADHD. A consent form was sent to parents to get permission for the students' participation in this research. In Tahvildari's school, the students who showed the symptoms of ADHD based on parents' form and teacher's form were omitted. In addition, those students who knew some words in the first pre-test were omitted, too.

Finally, eight ADHD and eight normal students were chosen. The participants' ages ranged from 12 to 14 years for ADHD students, with an average of 12.87 years $(\mathrm{SD}=0.64)$ whereas normal students' age ranged from 13 to 14 years, with an average of 13.25 years $(\mathrm{SD}=0.46)$. These participants were assigned both to the control and the treatment groups so that the researcher could compare each student's vocabulary learning by herself using two different ways of teaching.

\subsection{Procedure}

The participants recieved sixteen sessions' teaching period. Eight ADHD students participated in both the control and the treatment group. The same was done for the normal students. The alloted time for ADHD and normal students' vocabulary teaching were the same.

At first, teaching vocabularies by the flashcards and word lists were done in four sessions for the control group in both normal and ADHD students with one more repetition phase. One extra session in each phase was added during which the students just had a final post test of 32 words to determine how many words they could remember after a week. Because of the probable effect of focus strategies on the control group, the word list strategy was done first. Also, focus strategies (through key word method, concentration, making sentences by new words, fold overs) were taught for four sessions in the treatment group of ADHD and normal students with one more repetition phase. Because of ADHD students' attention losing with the time increasing, thirty minutes was alloted to both groups.

The words were selected from General Service List (GSL) of English words. This was a list of the 2000 most useful and frequent word families of English. Although this list has been criticized for many reasons, research done by Coxhead (2000) has shown that the General Service List (GSL) covers almost $80 \%$ of the academic texts and it would seem essential for any EAP student to know these word families.

Because these students were at the elementary levels, the words were selected based on the criteria of being noun, verb and adjective. All words were chosen as one or two syllables because the words with more than two syllables are difficult for elementary levels. The number of one or two syllable words was controlled in each session to be parallel.

At the beginning of each phase, a pre-test of 32 new words was given to all normal and ADHD students one week before to avoid generating any memory traces. The words were selected in such a way that the students could not have seen them in their books before. Also, these students had just studied English in school based on parents' forms that were analyzed before. The results of pre-test revealed that they know none of the new words. 
The days of teaching were kept to be four subsequent days in a week so that the conditions of teaching could be the same. After a week, eight words were taught in each session by repeating seven times giving Persian translation. Ten minutes were devoted to memorizing eight new words in the word lists. To measure the short-term improvement of the ADHD and normal students, a post-test (immediate post-test) was done immediately after finishing the teaching phase. The last session (after a week) was just devoted to testing the meaning of 32 words that the students remembered (delayed post-test). Based on Schmitt's view (2002), to avoid a serial learning effect, the order of the words in the pack was changed so that the meaning of one word could not remind the meaning of the next word in the pack.

In the treatment phase, 32 parallel words was given as a pre-test. All of the students got zero showing that they did not know them. After a week, four focus strategies were introduced in four sessions for the treatment group. In the first session, eight new words were taught through key word method. At first a new word was introduced by colorful flashcards showing the picture and spelling of the words. Then, the students were asked to make an association between new words (key words) and something that has about the same sound in their mother tongue or make a mental image between the keyword and English translation. A post test was done to determine how many words they could remember by this method.

Next session, eight new words were taught through showing the pictures by flash cards one by one. After showing each picture, the students were asked to close their eyes, make a focus and repeat three times after the teacher modeling and imagine the picture. Then, they opened their eyes and saw the spelling and wrote it in their notebooks. A post-test was given after teaching eight words through this strategy.

In the third session, eight new words were taught by flash cards (pictures and spelling). The students were asked to make a sentence by each new word. If they had trouble making a sentence, the teacher made it and the students repeated three times. A post-test of eight words was adminstered at the end.

In the forth session, eight new words were taught through fold overs technique. The students prepared a paper and wrote the new words that were shown by flashcards. They draw four coulumns and wrote Persian translations in front of words, they checked them with their notebook words. If they were right, they made a tick in front of them and if they were wrong, they corrected them. Next, they folded the first column of English words. By seeing Persian translations, they tried to write English equivalents. They checked them again and made a tick for the correct words. They then folded the second column. By seeing English words, they wrote Persian equivalents and checked them again. Such a repeatition could help the students to learn both Persian translations and English spellings. A post-test was done after teaching eight words by this technique. One more session (after a week) was just devoted for final post-test of 32 words.

As like as the control group, this process was repeated for the parallel words in the treatment group both for the normal and ADHD students. Type of the reliability of this study was parallel-forms reliability and t-test was used for the equality of collected data through SPSS software ( ver. 19).

\subsection{Research Design}

Through a quasi experimental design, the quantitative data was gathered from each student and was analyzed through two-way analysis of variance (ANOVA) in a factorial arrangement with two repetitions. The factors used in this study were:

A: characters in two levels of ADHD and normal students and

B: the strategies:

1.First strategy: two levels of word lists and focus strategies

2.Second strategy: five levels of word lists and four focus strategies

In the first stage, each of the focus strategies were compared with word lists strategy in each session seperately.

In the second stage, a mean of whole word lists scores was compared with four focus strategies in a factorial experiment. An orthogonal test was used to compare strategies together.

Independent variables of this study include teaching strategies which have two levels (focus and word lists) and dependent variable is students' vocabulary learning.

\subsection{Instruments}

A questionarie was given to the parents and English teachers for considering the students' behaviors at school and home. An interview with ADHD students was done by the psychologist at school. The instruments of this study consist of one pre-test and five post-tests. In the word lists stage colorful flashcards were used. During intervention phase colorful flashcards and focus strategies like key word method, concenteration, making sentences and fold overs were used. The collected data was analyzed through SAS 9.2 and SPSS 13 software.

\section{Results and discussion}

The results of this experiment were divided into three parts:

In the first part, the word list method was compared to the first focus strategy so that each session in the control group to be compared with its parallel focus strategy. In the second part, the mean scores of whole control group scores were compared with individual focus strategies. In the third part, final delayed post-tests in the control group and treatment group were compared together. The results of reliability study of collected data based on the t-test revealed that there 
was not any significant difference between two repetitions of control group and treatment group and assured the reliability of data.

3.1 The results of analysis of variance of immediate post-tests in the control group with individual focus strategies

The results of analysis of variance on the data obtained from the first immediate post-test (in terms of comparison by the scores of two groups) to compare word lists and key word method in ADHD and normal students showed that there was a significant difference between ADHD and normal Students at 5\% probability level (Table 1).

Table 1. The analysis of variance for the effects of students characters and methods of teaching on voc. achievement

\begin{tabular}{|c|c|c|c|c|c|c|}
\hline \multirow[b]{2}{*}{ Source } & \multirow[b]{2}{*}{ Df } & \multicolumn{5}{|c|}{ Mean Square } \\
\hline & & Test 1 & Test 2 & Test 3 & Test 4 & Final test \\
\hline Model & 4 & $880.719 * *$ & $869.422 * *$ & $834.109 * *$ & $902.500 * *$ & $672.391 * *$ \\
\hline Character & 1 & $6.250 *$ & $9.766^{*}$ & $15.016^{* *}$ & $1.000^{\mathrm{ns}}$ & $4.516^{\mathrm{ns}}$ \\
\hline Method & 1 & $5.063 *$ & $.391^{\mathrm{ns}}$ & $.391^{\mathrm{ns}}$ & $9.000 * *$ & $19.141 * *$ \\
\hline character $*$ Method & 1 & $1.000^{\mathrm{ns}}$ & $1.266^{\mathrm{ns}}$ & $.391^{\mathrm{ns}}$ & $.000^{\mathrm{ns}}$ & $.766^{\mathrm{ns}}$ \\
\hline Error & 60 & 1.019 & 1.722 & 1.343 & .900 & 2.391 \\
\hline Total & 64 & & & & & \\
\hline
\end{tabular}

*,** and ns shows significant at 5\%,1\% and non-significant respectively

The mean score in normal students was 7.71 and in ADHD ones was 7.09 (Table 2). Because of the significance of $F$ parameter belong to this source of variation, the normal students demonstrated better scores in both levels of teaching (the word lists method and focus strategies).

Table 2. means of scores in word lists and individual focus strategies in normal and ADHD students

\begin{tabular}{llrrrrr}
\hline & & \multicolumn{5}{c}{ Mean } \\
\cline { 3 - 7 } Character & Normal & 7.719 & 7.750 & 7.688 & 7.625 & 6.719 \\
& ADHD & 7.094 & 6.969 & 6.719 & 7.375 & 6.188 \\
\cline { 3 - 7 } Method & & & & & & \\
& 1.00 & 7.125 & 7.281 & 7.125 & 7.125 & 5.906 \\
& 2.00 & 7.688 & 7.438 & 7.281 & 7.875 & 7.000 \\
\hline
\end{tabular}
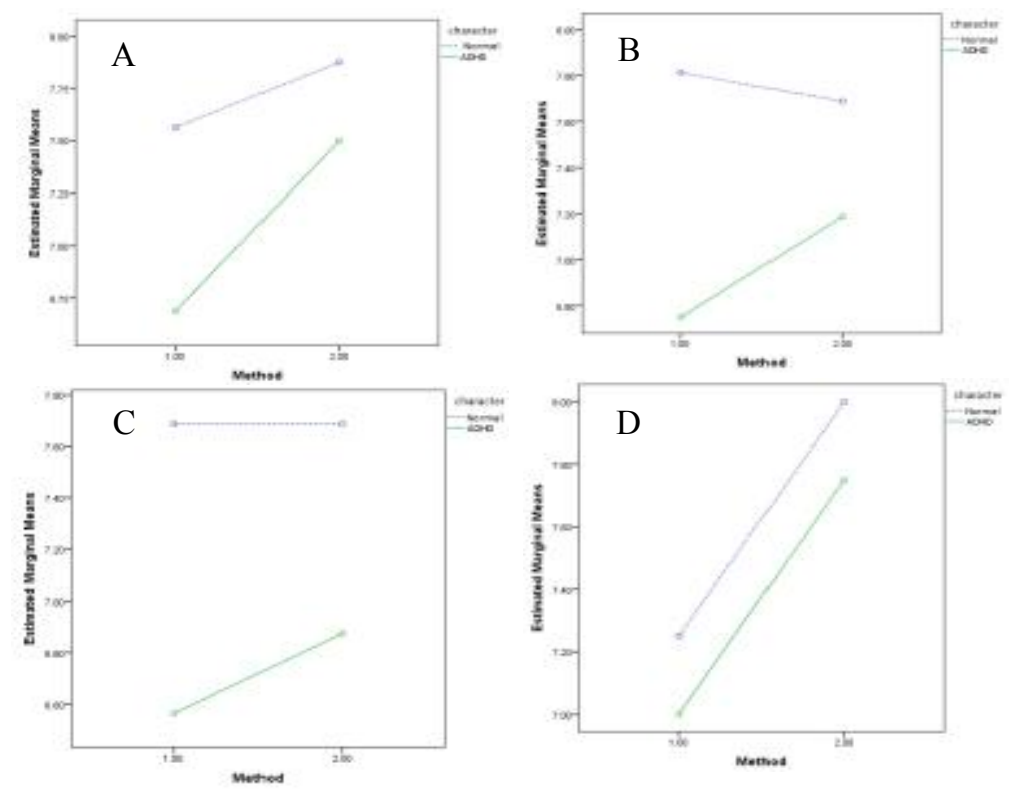

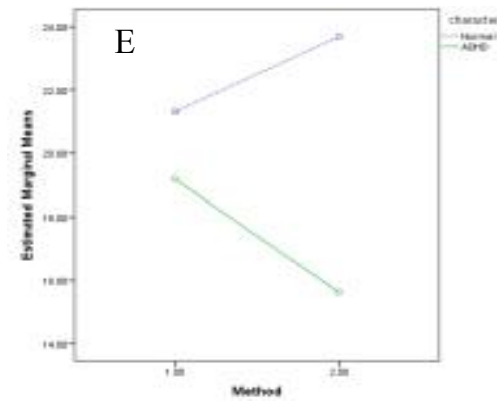

Fioure 1 Interaction of character and method in different tests 
The results of analysis of variance showed that there was a significant difference (5\%) between the word lists method and the first focus strategy (Table 1). The mean of scores in the word lists (7.12) and the key word method (7.68) revealed that the key word method was better than the word lists in both normal and ADHD students (Table 2). It agrees with Jenpattarakul's study (2012) who investigated the impact of keyword technique on the normal students' vocabulary retention ability in an EFL class and the results from his study supported that using keyword technique helped the students store and retrieve a new bunch of vocabularies, motivated them to learn English language and expanded their imagination and creativity. Also, it agrees with Baleghizadeh and Ashoori's study (2010) that showed that the key word method produced better recall when compared to the word lists method .

In addition, Tootkaboni (2012) compared the effects of three strategies (key word, context and word list) on long term retention of English vocabulary items in the normal students and concluded that the keyword group was significantly better than other groups in both cued-recall and word-recall tests and there was generally no significant difference between the context and wordlist. Regarding mnemonic strategies, Thompson (1987) concluded that mnemonic aids, particularly the keyword method, help learners to memorize words more effectively. Pressley, Levin, and McDaniel (1987) emphasized that through mnemonic aids such as the keyword method a direct link is made between the word and the associated definition.

The results of the present study can be construed in terms of depth-of information-processing (Craick \& Lockhart, 1972; Craik \& Tulving, 1975). Based on the depth-of information-processing theory, the more information is processed at deeper levels, the more retention is gained.

However, there was not a significant interaction between character and method (Figure 1A). The first post-test demonstrated that word lists' scores were lower than key word method in both normal and ADHD students.

The mean comparison of the control group with the treatment group in normal and ADHD students was not significant ( $\mathrm{P}=0.3847$ \& $\mathrm{P}=0.264$ respectively). The mean of control group in the normal students was significantly $(\mathrm{P}=0.0171)$ different from the control group in ADHD students but there was not any difference between the treatment group in normal students and the treatment group in ADHD students. This analysis revealed that focus strategy had better effect on ADHD students than normal students.

The comparison of the word lists (control group) and the concentration strategy on the second post-test demonstrated that there was a significant difference between the character of normal and ADHD (Table 1). The normal students (7.75) performed better than ADHD students (6.96) in both control and the treatment group (Table 2) and ADHD students' scores were higher in the concentration strategy than the word lists method although the analysis was not significant while there was no difference between the methods of the word lists and the concentration strategy from analysis view point. It showed that the kind of teaching made no difference in both normal and ADHD students in spite of the fact that the scores showed a little improvement in the concentration strategy. The interaction was not significant in both ADHD and normal students (Figure 1B). No experimental study was found to approve or reject these results. The comparison of means of the control group with the treatment group in the normal and ADHD students was not significant $(\mathrm{P}=0.7885 \& \mathrm{P}=0.3495$ respectively). The mean of control group in normal students was significantly $(\mathrm{P}=0.0255)$ different from the control group in ADHD students but there was not any difference between the treatment group in the normal students and the treatment group in ADHD students.

In the third post-test, the control group was compared with the third focus strategy (making sentences with new words). It was seen a highly significant difference (0.01) in character (normal and ADHD), but it was not significant in method and interaction. Using target words to compose sentences is a kind of generation task, because the semantic connection between the target word and the whole sentence has been built, i.e. the learner uses a target word to compose a sentence, then she should think about how to use the word in a sentence and how to combine the target word with other words in the sentence.

Although learning words from lists is considered to be a rather traditional way to learn vocabulary, and most researchers claims that teaching vocabulary in a communicative way is the most effective way to learn vocabulary, some researches indicate that "studies comparing incidental vocabulary learning with direct vocabulary learning show that direct learning is more effective" (Schmitt, 2002; cited in Yu, 2010, pp.11-12).

Mean scores in the normal students (7.68) was significantly higher than ADHD (6.71) students (Table 2). Although the word lists method in the control group was lower than the third focus strategy in both ADHD and normal students but there was not a significant difference between them. The focus strategy in ADHD students improved their learning situation, there was not seen any improvement in the normal students. Meanwhile, the normal students always got better scores than ADHD students. It showed that the level of learning was always high in normal students. (Figure 1c)

The comparison of mean of the control group with the treatment group in the normal students was significant $(\mathrm{P}=0.0079)$ while in ADHD students was not significant $(\mathrm{P}=0.4486)$. Also, when the control group in the normal students was compared to the control group in ADHD ones, the result was significant $(\mathrm{P}=0.0079)$, too. Meanwhile, the mean of the treatment group in the normal students was not significant than this mean in ADHD students $(\mathrm{P}=0.0519)$.

Yu (2011) investigated a comparison of two methods, the word lists and sentence writing (that requires pupils to memorize new words by making up their own sentences in order to establish links between old and new knowledge) and the results demonstrated that pupils who learn words using word lists only remember words in the short-term retention, while the sentence writing method results in greater long-term retention. It seems that the students' level of 
learning is an important factor for utilizing this strategy because the students who are in elementary level of learning have more problems to make sentences than intermediate and advanced levels.

The last post-test in control group was compared with the last focus strategy (fold overs). The analysis of variance revealed that the character of the students did not have any significant effect on the learning and there was no difference between them in learning. There was a difference between using word lists and fold overs so the method was significant at the level of $5 \%$. The interaction was not significant. The mean scores in the normal ones (7.62) was higher than ADHD (7.37) but it was not significant (Table 1 and 2). The forth focus strategy (fold overs) had a significant effect on the learning in comparison to the word lists (Figure 1D). The vocabulary learning in both normal and ADHD students increased based on the forth focus strategy and the students felt more satisfied using this strategy. No experimental study was found to analyze and compare the effect of fold overs strategy on vocabulary learning of students.

The results of comparison between the control group and the treatment group in the normal and ADHD students was significant $(\mathrm{P}=0.0291)$. The control group in the normal and ADHD students and the treatment group in the normal and ADHD students were not significant ( $\mathrm{P}=0.4590, \mathrm{P}=0.4590$ respectively). In both normal and ADHD students, fold overs strategy had a significant impact on the learning of students ( $\mathrm{P}=0.0291$ and $\mathrm{P}=0.0291$ respectively).

\subsection{The results of the comparison of means scores of whole control groups score with individual focus strategies}

To consider the different learning strategies, the analysis of variance was done to compare the mean scores of the control group with the different focus strategies (Table 3).

Table 3. Analysis of variance among different learner character and learning strategies

\begin{tabular}{lccccc}
\hline Source of variation & Df & Type III Sum of & Mean Square & F & Sig. \\
& & & & \\
\hline Model & 9 & 25.2660156 & 2.8073351 & 3.51 & 0.0006 \\
Char & 1 & 12.23789063 & 12.23789063 & 15.29 & 0.0001 \\
Method & 4 & 10.87343750 & 2.71835937 & 3.40 & 0.0108 \\
method control vs all & 1 & 4.22500000 & 4.22500000 & 5.28 & 0.0230 \\
method control vs Focus1 & 1 & 4.38378906 & 4.38378906 & 5.48 & 0.0206 \\
method control vs Focus2 & 1 & 1.19628906 & 1.19628906 & 1.50 & 0.2234 \\
method control vs Focus3 & 1 & 0.21972656 & 0.21972656 & 0.27 & 0.6010 \\
method control vs Focus4 & 1 & 8.08691406 & 8.08691406 & 10.11 & 0.0018 \\
method Focus1 vs Focus2 & 1 & 1.00000000 & 1.00000000 & 1.25 & 0.2654 \\
method Focus1 vs Focus3 & 1 & 2.64062500 & 2.64062500 & 3.30 & 0.0713 \\
method Focus1 vs Focus4 & 1 & 0.56250000 & 0.56250000 & 0.70 & 0.4031 \\
method Focus2 vs Focus3 & 1 & 0.39062500 & 0.39062500 & 0.49 & 0.4858 \\
method Focus2 vs Focus4 & 1 & 3.06250000 & 3.06250000 & 3.83 & 0.0523 \\
method Focus3 vs Focus4 & 1 & 5.64062500 & 5.64062500 & 7.05 & 0.0088 \\
char*method & 4 & 2.15468750 & 0.53867187 & 0.67 & 0.6116 \\
Error & 150 & 120.0273438 & 0.8001823 & &
\end{tabular}

There was a significant difference between the characters and the methods source of variation. The interaction was not significant. By comparing the control group with all of the focus strategies it was revealed that there was a significant difference (5\%) both in ADHD and normal scores and the students performed better using focus strategies.

The orthogonal test showed that the control group was significantly different from the first strategy. There was no significant difference between the control group and the second strategy. The comparing of the control group and the third focus strategy showed that there was no significant difference between them. The control group and the forth focus strategy were significantly different and the forth strategy was better than the word lists. Also, it was revealed that there was no significant difference between the first focus strategy and the second focus strategy, the first focus strategy with the third focus strategy and the first focus strategy with the forth focus strategy. When the second focus strategy was compared with the forth focus strategy, the results showed that it had a probability close to significant $(\mathrm{P}=0.0523)$. But the third focus strategy had a significant difference with the forth focus strategy. So, the best strategy was the last one. The first and the last strategy performed better than the second and third strategy.

Figure 2 shows that the control group scores were low in both ADHD and normal students. The first focus strategy improved the scores both in ADHD and normal students. The second and third strategy improved the scores but it was not as well as the first one and the forth strategy improved well. 


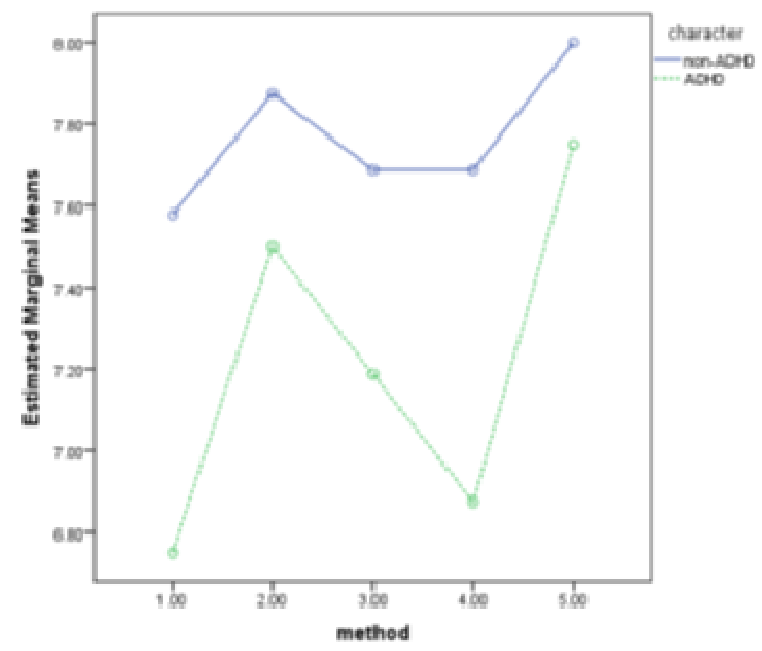

Figure 2: Investigation of interaction between character and strategies method (1: word lists 2: keyword method 3: concentration 4 : fold overs)

\subsection{The results of analysis of final delayed post-tests in the control and the treatment groups}

The final analysis was performed to study the long term recall of students. The ANOVA showed that there was a significant difference between ADHD and normal students, while the difference between methods and interaction was not significant. The normal students got higher scores than ADHD students. The Kind of method (word lists or focus strategies) made no difference in long term remembering of words. The interaction was not significant but it was close to significant. The mean of scores increased in normal students using focus strategies but it decreased in ADHD students (Figure 1E). The difference between the control group and the treatment group in normal students was not significant $(\mathrm{P}=0.2897)$. Also, this mean in ADHD students was not significant $(\mathrm{P}=0.1144)$. The difference between the control group in normal and ADHD students was not significant $(\mathrm{P}=0.3431)$ and the difference between the treatment group in both groups was significant $(\mathrm{P}=0.0006)$, too.

One important fact is that vocabulary is not explicitly taught in schools, and the students are usually expected to learn vocabulary on their own. The students mostly apply the word lists strategy and are not aware of learning strategies. The purpose of this study was to investigate whether the focus strategies has any effect on vocabulary learning of ADHD students. Considering it more accurate, the normal students were compared, too. It should be mentioned that no experimental research was found to consider the effect of focus strategies on vocabulary learning of ADHD students. Either most of the research was found on vocabulary learning of the normal students or it was tried to see the effects of the strategies on the behavior of ADHD students while inattentive type of ADHD especially in girls ones do not have much behavior problems. Most of them are easily distracted, disorganized and forgetful. Some of them are too talkative, interrupt others but others are very quiet and are always daydreaming (as the girls participated in this research ).

The results were in accordance with the first hypothesis of this study. When the ADHD students used the focus strategies, they outperformed compared to the word lists as shown in the immediate post-test but the first and the last focus strategies had significant effects on ADHD students' vocabulary learning from analysis point of view. The results of the first focus strategy supports to the findings of Nation (2008) who showed that the key word technique contributes to the improvements of students' vocabulary retention ability. Also, the students of this study agreed that the keyword technique made them aware of correct pronunciation of English words, helped them to try to learn the words accurately and motivated them to learn the words by increasing their imagination and creativity. Although the second and third strategy increased the amount of learning, it was not significant. The results of this study on EFL students showed that sentence making did not improve the level of learning and the students found it difficult but Yu (2011) indicated that learning words by sentence writing on ESL students results in long term retention. Regarding the third strategy (concentration), O'Malley et al. (1985) found that Asian students resist using the strategies for imagery and rely on rote memorization strategy. Also, the longer they remain in a program, the more they prefer the strategy. All in all, the ADHD students showed particular strengths in the vocabulary learning, suggesting that focus strategies could help the students to focus on learning but it needs to be practiced more and determined based on their level of learning. It also seems that presenting new and suitable strategies by teachers helps the students to focus on their own specific needs as well as allowing them to access their materials on their own time. The amount of vocabulary learning in ADHD students increased from pre-test to the delayed post-test but this increase was higher in the control group in comparison to the experimental group in ADHD students but the normal students outperformed in the experimental group. Because of the ADHD students' cognitive problems, they may acquire new skills slowly and have difficulty following directions especially multiple directions. They may be able to learn information in one way but not in another. Because of short attention span, they may find it difficult to memorize information. Also, they may have different learning styles. 
The second hypothesis was in line with the results of this study. It was revealed that normal students mean scores in the experimental group was higher than the control group especially the first and the last focus strategies were significant and the best strategy was the last focus strategy. This study has taken a step in the direction of justifying the inclusion of focus strategies for ADHD and normal students' vocabulary learning. The strategies outlined in this study should be replicated with other EFL or ESL students as well as other levels in order to be able to recommend the use of focus strategies for all students.

\section{Conclusions}

Working with ADHD students is a great challenge and many teachers and parents become frustrated confronting to them. Regarding English teaching, an extra load is felt upon them. Vocabulary development cannot achieve just by traditional strategy. The teachers should help learners develop different strategies to convey meaning and organize lexical items for storage and late retrieval. This leads to learner autonomy and academic success which is the goal of teaching. So, based on the belief that 'no child left behind', this study was designed to explore the effectiveness of focus strategies on vocabulary learning of ADHD students. To get the best result, normal students were compared with ADHD students .

The students (both normal and ADHD ones) were assigned to the control group and the experimental group. In the control group, the vocabularies were taught through word lists. In the treatment group, the vocabularies were taught through four focus strategies. The quantitative data was gathered from each student and was analyzed through 2-way analysis of variance in a factorial arrangement with two repetitions. The findings showed that the students outperformed in first and last focus strategies in comparison to word lists both in ADHD and normal students. Generally focus strategies revealed better results in immediate post-tests, especially in ADHD students. It means that retention and recall was better using focus strategies but delayed post-test did not reveal the expected results (the scores decreased in the experimental group of ADHD students). So, it may be concluded that in elementary levels of teaching the more emphasis should be given to repetitions of words. Focus strategies would help provided that necessary practice and exposure to words had been done before. In addition, ADHD students are capable of effective acquisition of lexis, provided that appropriate teaching strategies are implemented. If focus strategies are done in longer periods of time with much practice and familiarity or in combination to the word lists strategy, the results may be changed. Finally, language is the most complex skill that human beings master and many internal and external factors can hinder the teaching and learning process.

\subsection{Pedagogical implication}

Based on the results of this study, the students should be exposed to new strategies for learning vocabularies. Some teachers do not present different learning strategies to students. They need to be knowledgeable to these strategies and introduce them so that the students to be self-directed learners. If the students could find suitable strategies and use them, the students' vocabulary size would be increased. These strategies would be helpful both for ADHD and normal students. Also, most studies related to ADHD have been focused on pharmacological interventions. If suitable strategies are introduced to ADHD students, they may need less prescription of stimulant medicine which may have side effects on them.

So, it is necessary for teachers to educate themselves to different learning difficulties in students, to be aware of them and implement variety of teaching styles in the classroom. They need to identify and to be patient with learning problems in ADHD students in the classroom. Such students need extra accommodations and help. If they are behaved in an appropriate way, their motivation and self-esteem would be increased and they would overcome their difficulties at school, at home and in the society. Some teachers and parents believe such students never progress whatever effort is attempted and this is simply how their brain functions but recent results in neurology and human brain development show, this is not true at all (Shaw, 2001; Schwartz, 2003; Doidge, 2007; Goldberg \&Fernandez, 2009). If the teachers instruct properly, these students are able to experience not instant but sustainable academic success. Each student with ADHD has a unique characteristic so teachers' learning style needs to be in line with different learning styles in ADHD students and the strategies should allow the student the best chance of success. Also, the teachers should find the reason of poor grades in the students. The reason of inattention may be the student preoccupied by anxious thoughts; teacher's lesson may be poorly planned or presented in a disorganized manner. Also, classroom setting needs to be arranged. Teachers, who focus on making their instruction predictable, ordinary and motivating, can hold the attention of most of the students most of the time.

\subsection{For further studies}

Although much progress has been made in our understanding of treatment of ADHD, much has to be researched. Further research on this topic might include continuing the intervention phase for longer period of time for strategies which are suitable for elementary levels and choosing and trying the second and third focus strategies of this study for middle and advanced levels. Also, this study investigated the effect of focus strategies in girls who had inattentive type of ADHD. It is recommended a research on hyperactivity or combined type of ADHD which is more common in boys especially in elementary schools. Because the domain of ADHD problem is very wide and the diagnosis of this problem is increasing in schools, other areas (like listening, speaking, reading, writing, as well as grammar) could be a good subject for further research. The researchers did not find any experimental study on this topic. Further research would be useful to gain more insights into focus strategies on vocabulary learning of ADHD students. 


\section{References}

American Academy of Pediatrics (2000, May).Clinical Practice Guideline: Diagnosis and Evaluation of the Child with Attention-Deficit/Hyperactivity Disorder. Pediatrics, 105 , 1158- 1170.

Aizer. A. (2008). Peer effect, institution, and human capital accumulation: The externalities of ADD. Retrieved, September 11, 2013 from www.nber.org/ papers/w 14354

Armstrong, T. (1999). AAD/ ADHD alternatives in the classroom. Retrieved, August 15, 2013 from http :// www .ascd .org/ publications /books /199273/ chapters /Strategies -to-Empwer-Not-Controls-Kids-LabeledADD ADHD.aspx

Baleghizadeh,S. \& Ashoori,A. (2010).The effect of keyword and wordlist methods on immediate vocabulary retention of EFL learners.Pakistan Journal of social sciences (PJSS).30(2), 251-261.

Bolin, J. E.(2010).Improving the classroom for students: What are effective instructional strategies for children with attention deficits. Retrieved, September 18, 2013, from www.cehs.ohio.edu/gfx/media/polf/bolin.polf

Craik, F. I. M., and Lockhart, R. S. (1972). Levels of processing: a framework for memory research. Journal of Verbal Learning and Verbal Behavior, 11, 671-684.

Gadow,K.d., Sprafkin,J.(1994).Child Symptom Inventories manual.Stony Brook,Ny: Checkmate Plus.

Grunter, J. A. (2013). An update in attention deficit / hyperactivity disorder. Retrieved,September1,2013,fromhttp://www.Formularyjournal.modernmedicine.com/formlaryjournal/news/tags/stimul ants/update-attention-deficithyperactivity-disorder

Gurian,A. (n.d.). Girls with ADHD:overlooked, underdiagnosed, and underserved. Retrieved February 22, 2014, from http ://www.aboutourkids/articles/girls-adhd-overlooked-underdiagnosed-underserved

Jenpattarakul,W.(2012). The impact of keyword technique on the students' vocabulary retention ability in an EFL class. Mediterranean Journal of social sciences,3(3),565-573.

Kingsley, R. S. (2012). What is ADHD. Retrieved, January 31, 2013, from http: // www.Kidshealth.org/parent/medical/learning/adhd.html

Mohammad Esmaeili, E. \& Alipour, A. (2002). Reliability and validity of the Child Symptom Inventory-4 (CSI-4). Research of Exception Children,2 (3), 239-254.

Nation, I.S.P. (2008). Teaching vocabulary (strategies and techniques). Boston: Heinie.

O'Malley, J. M. et al (1985). Learning strategies application with students of English as a second language. TESOL Quarterly, 19, 285-296.

Oord, Bogels, \& Peijnenburg. (2012) . The effectiveness of mindfulness training for children with ADHD and mindful parenting for their parents. Journal of child and family studies, 1,139-147.

Parker, H. C.(2006).Problem solver guide for students with ADHD. United States of America: Speciality Press.

Pressley, M., Levin, J. R., \& McDaniel, M. A. (1987). Remembering versus inferring

what a word means: Mnemonic and contextual approaches. In McKeown, M. G. \& Curtis, M. E. (Eds.), The Nature of Vocabulary Acquisition (pp.107-127). Hillsdale, New Jersey: Lawrence Erlbaum Associates.

Scott, V. C, \& Fark, K. (2011). Teaching students with ADHD to F.O.C.U.S: A learning strategy.RetrievedSeptember15,2013,fromwww./education.jhu.edu/PD/newhorizons/journals/winter2011/Scott

Shaw, C. A., McEachern, J. C. (2001). Toward a Theory of Neuroplasticity.

Schmitt, N. (2002). An Introduction to Applied Linguistics. London: Arnold.

The five principles of effective second language acquisition. (2014). Retrieved, July 3, 2014,from www.transparent.com/second language.html

Thompson. I. (1987). Memory in language learning. In A. Wenden 8J. Rubin (Eds).Learner Strategies in Language Learning. (pp. 15-30). Newjersy: Prentic-Hall.

Tootkaboni,A.A.(2012).Recall of foreign-language vocabulary:Effects of keyword, context and wordlist instructional strategies on long term vocabulary recall of EFL learners.Journal of theory and practice in education,8(1),54-71.

Turketi, N. (2010). Teaching English to children with ADHD. Retrieved August 15, 2013, from http://www.digitalcollections.Sit.edu/ipp-collection/483

Yu, L. (2011).Vocabulary recognition and memorization: A comparison of two methods. Retrieved March 30, 2014, from http://www.diva-portal. Org/smash /get / diva 2:429600/FULLTEXT01.pdf

\section{Appendices}

\section{Appendix A}

Sample of parent's form, English version:

Dear parents,

Hello. Regarding to the importance of identifying the learning difficulties, attention and focus problems, and hyperactive behaviors of students that could make a lot of difficulties during the students learning, our research group is trying to identify such students to consider the efficient teaching and learning methods. So, your help and favor for completing this question form means that you give importance to increase all and your student's learning. It's essential to mentbion that obtained data will be confidential and you'll be aware of the results of this study soon. 
Personal information:

1. Date of study

2. Name

3. Date of birth

4. Sex

5. Whether your student is under the treatment of psychologist? Yes No

If yes, mention the kind of treatment. Pharmacological or non-pharmacological

6. Whether your student is going to English institutes? Yes No

\section{Appendix B}

Sample of teacher's and parent's form questions, English version:

Dear parents/ teachers

After reading each statement, determine which answer in answer sheet (never- sometimes-often- nearly always) is in line with your student's behavior at home/school.

1. Often fails to give close attention to details or makes careless mistakes in school work and other activities

2. Often has difficulty sustaining attention in tasks or play activities

3. Often doesn't seem to listen when spoken to directly

4. Often doesn't follow through on instructions and fails to finish schoolwork or chores

5. Often has difficulty organizing tasks and activities

6. Often avoids, dislikes or is reluctant to engage in tasks that require sustained mental effort, such as schoolwork or homework

7. Often loses items necessary for tasks or activities (for example, toys, school assignments, pencils, books)

8. Is often easily distracted

9. Is often forgetful in daily activities

10. Often fidgets with hands or feet or squirms in seat

11. Often leaves seat in classroom or in other situations when remaining seated is expected

12. Often runs about or climbs excessively in situations when it's inappropriate

13. Often has difficulty playing or engaging in leisure activities quietly

14. Is often "on the go" or often acts as if "driven by a motor"

15. Often talks too much

16. Often blurts out answers before questions have been completed

17. Often has difficulty awaiting turn

18. Often interrupts or intrudes on others' conversations or games

Appendix C

Sample of pre-test and final delayed post-test

Translate these words into Persian.

$\begin{array}{llll}\text { 1. finger } & \text { 9.nail } & \text { 17.forward } & \text { 25.end } \\ \text { 2. coin } & \text { 10.rope } & \text { 18.accept } & \text { 26.hammer } \\ \text { 3. waist } & \text { 11.star } & \text { 19.earth } & \text { 27.brass } \\ \text { 4. sing } & \text { 12.left } & \text { 20.safe } & \text { 28.donkey } \\ \text { 5. paw } & \text { 13.rich } & \text { 21.glad } & \text { 29.rug } \\ \text { 6. purse } & \text { 14.diamond } & \text { 22.cage } & \text { 30.chest } \\ \text { 7. line up } & \text { 15.juice } & \text { 23.cow } & \text { 31.cupboard } \\ \text { 8. stormy } & \text { 16.bear } & \text { 24.church } & \text { 32.salt }\end{array}$


Sample of immediate post-test

Translate these words into Persian.

1 .brass

2 .end

3. hammer

4 .donkey

5 .rug

6. chest

7. salt

8. cupboard

\section{Appendix D}

Sample of consent form, English version

\section{Consent form}

We..... Parents of

(the child's name) in grade........do hereby give our consent for participating our daughter in the educational research study of "The effect of focus strategies on vocabulary learning of ADHD students". Participation in research study is voluntary. Our child is free to decline to participate in this research study, or we may withdraw her participation at any point without penalty. This decision whether or not to participate in this research study will have no influence on her present or future status at.......Junior High School. Meanwhile, all obtained information will be confidential and the results of this research will be announced anonymously.

Parents signature

Student $\quad$ signature

Telephone number 